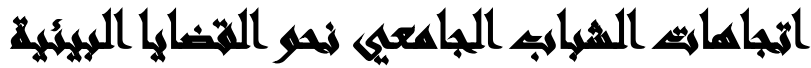

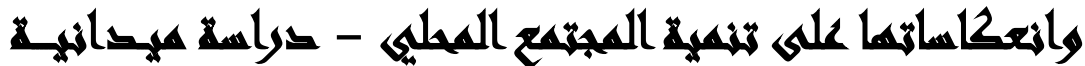

\section{[IV]}

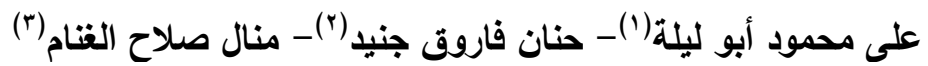

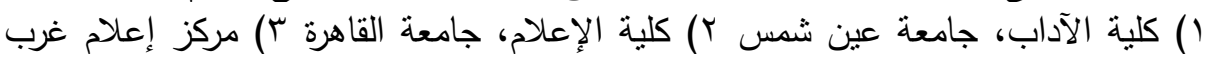
القاهرة، الهيئة العامة للاستعلامات جاتئ

\section{المستخلص}

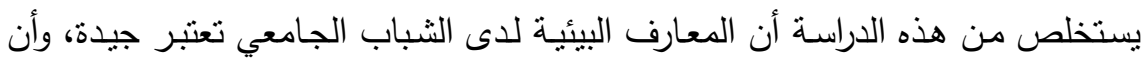

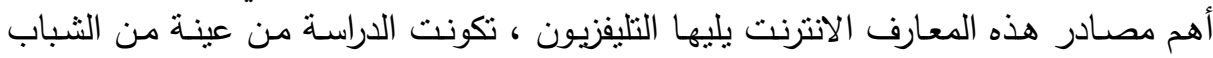

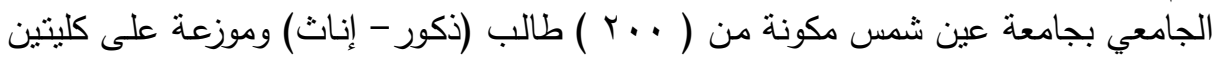

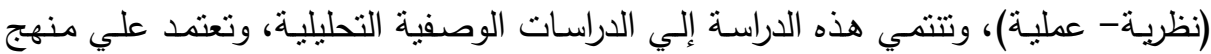

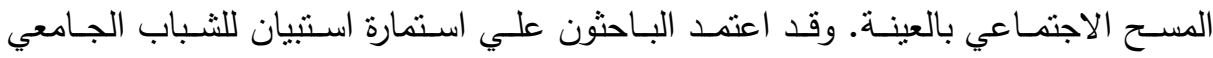

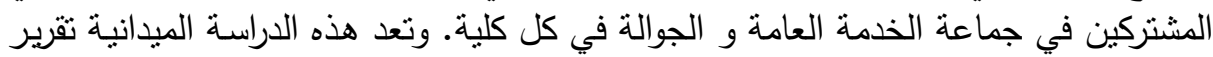

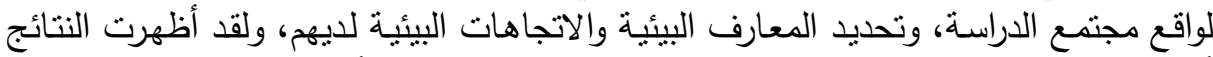

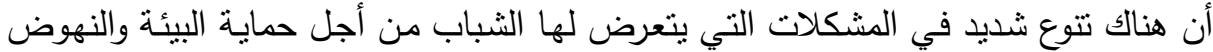

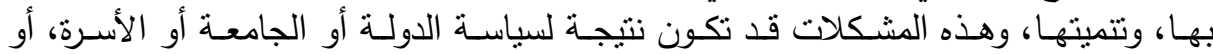

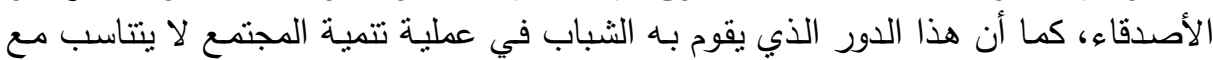

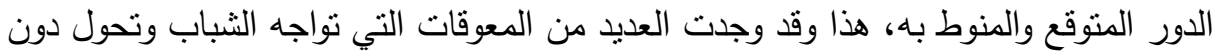

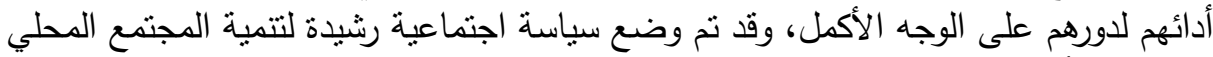

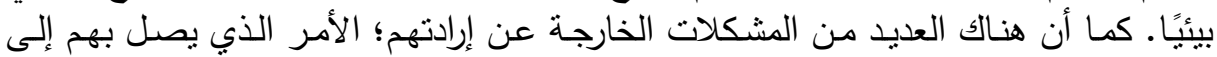

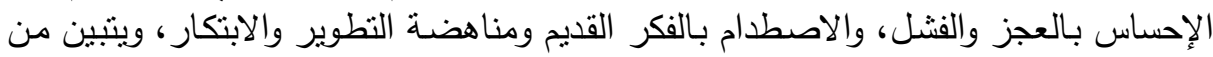

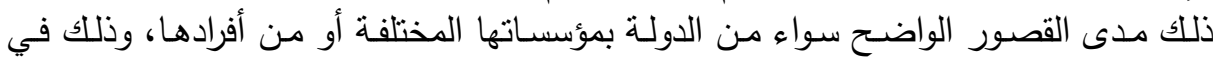

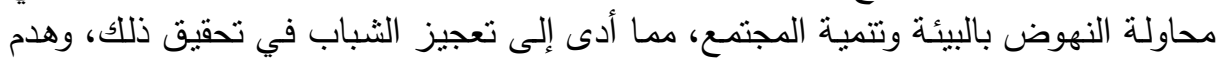

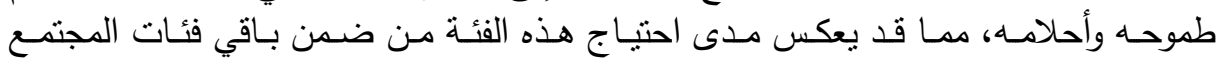

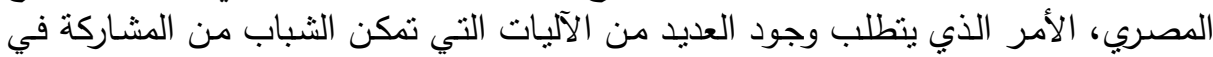
تتمية المجتمع المحلي. 


\section{المهابs}

تتمركز عمليـة التتميـة حول البيئة والاهتمـام بها وبالإنسـان، فـلا بيئة بدون إنسـان ولا

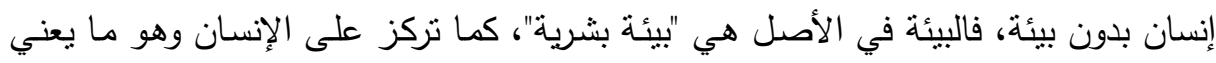

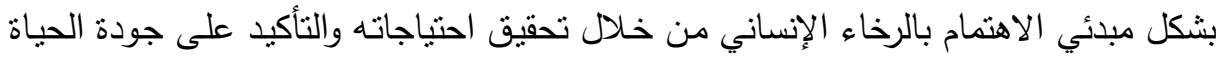

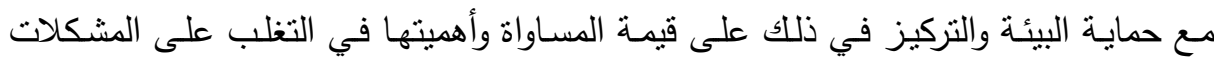
البيئية المختلفة، والنهوض بالمستوى الاقتصادي والاجتماعي والبيئي والعمراني لجميع السكان.

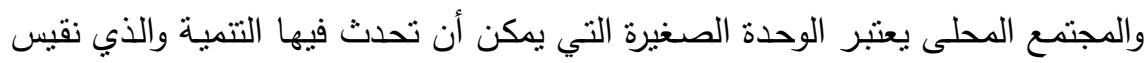

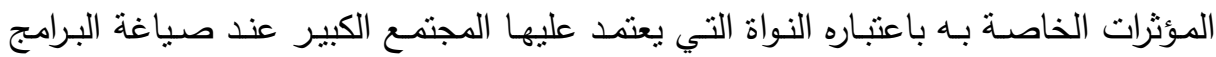
والخطط.. أي أنه بمثابة "بيت الخبرة" للمجتمع الكبير وصانعي القرار السياسي والاجتماعي والاقتصادي، والبيئي، وهذا ما يجعلنا نقول بأن تتمية المجتمع المحلى وسيلة من وسائل تتمية المجتمع القومي الكبير، وذلك لأن المجتمعات المحلية هي وحداته التي يتألف منها، وأن هذه ونه التتمية تكون من أجل مواجهة حاجات الناس في المجتمع المحلى. وفي ظل السعي وراء عملية التتمية أهملت المشاكل المتعلقة بفرص بقاء بقاء الإنسانية في ظروف الأزمات البيئية الكونية؛ حيث يمكن ملاحظة الانخفاض النسبي في اهتمام كل من الجماعة العلمية والمجتمع السياسي بنلك المشاكل خاصة في ظل غئل فياب الطرق الواقعية لحل مثل هذه المشاكل البيئية، وتطرح بروز هذه المشاكل البيئية وتفاقم حدتها تحدث عدة تحديات غير منظورة للعلوم الاجتماعية وللاهتمامات اليومية للمواطنين والحكومات والمصالح الخاصة، لهنه وبسبب تعاظم خطر تلك المشاكل من جهة، وتقلص نسبة الموارد على الأرض وإضعاف إضلى

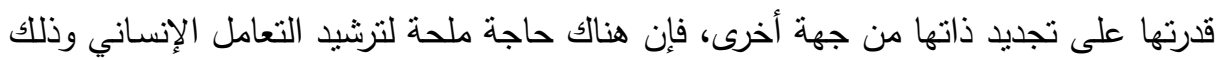

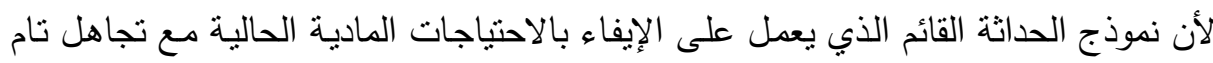

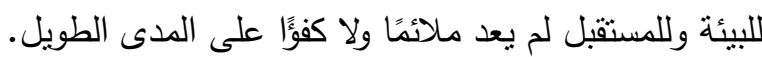
لذا فمن الضروري الاعتراف بأن القضايا البيئية هي قضايا اجتماعية ونقافية، وأنه في لئي

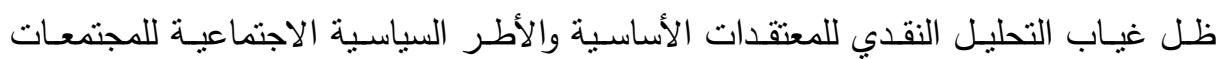

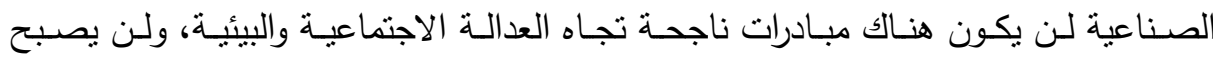


المجتمـع الحديث في وضـع بسمح لـه بـالتكيف مـع رؤية عالمية بديلة وبنـاء سياسي وتقافي واجتماعي قادر على دعم بروز مجتمع مستدام بيئيًا وتتمويًا.

\section{هشكلة الدراسة}

لقد تزايــــا الاهتمـام بالبيئة وقضـاياها في السـوات الأخيرة بصـورة واضـحة، وأصبحت تستحوذ على اهتمام الدول المتقدمة، والنامية على حد سواء، وتؤكد التقارير الدولية أن العالم

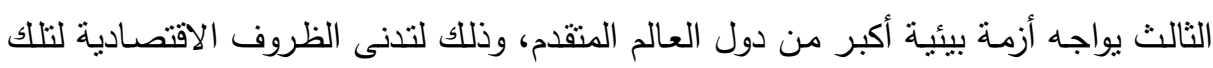

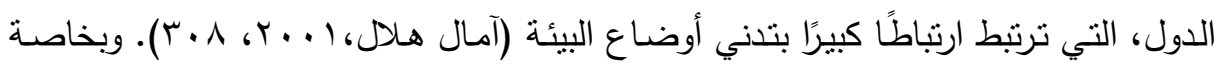

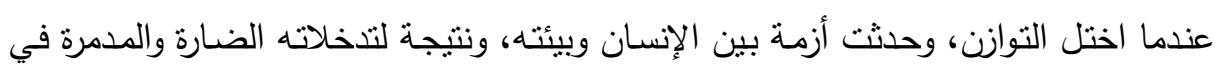

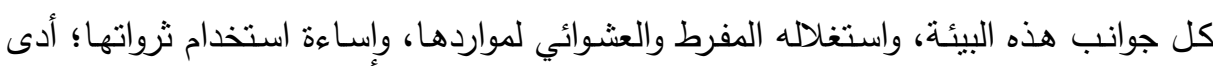

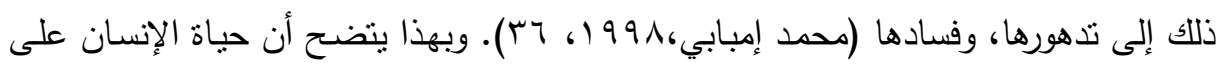

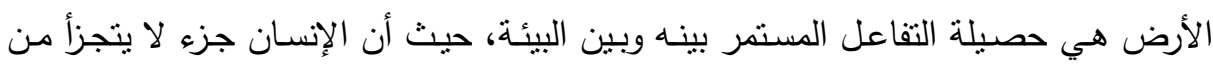

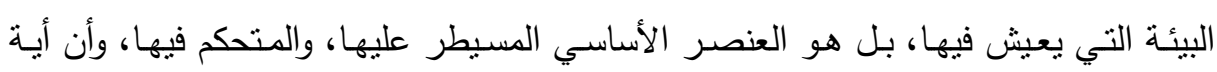

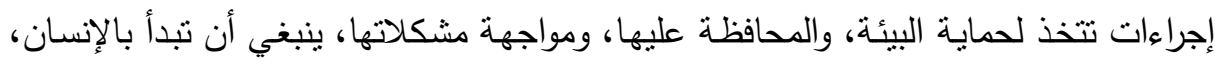

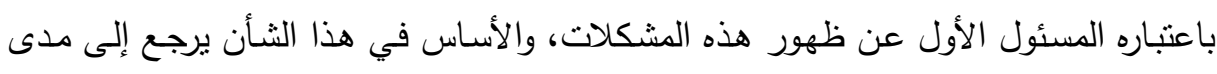

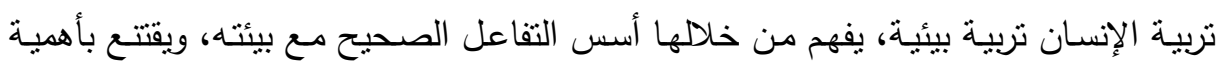

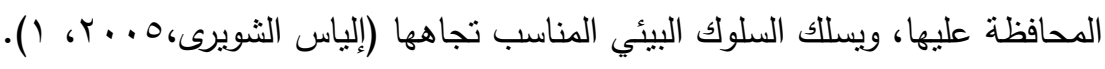

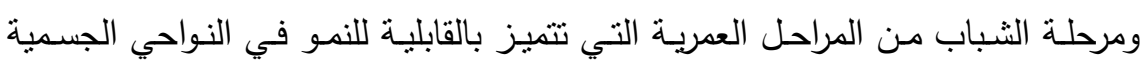

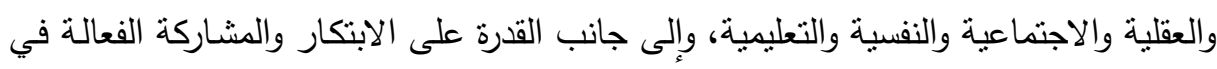
كل القضايا التي تهم مجتمعاتهم، فأصبح الثباب يمثل مركز الهتمام الباحثنين لدوره المحوري

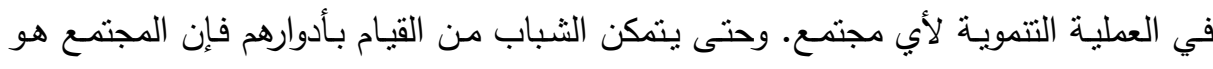

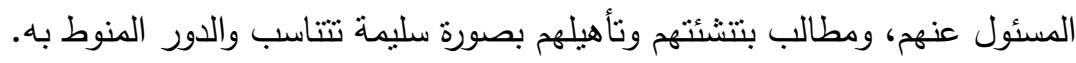


وأصبح العمل مـع الثباب على أسـاس تخصصي واحدًا من الاتجاهـات الرئيسية التي بدأت تشق طريقها في غالبية البلدان والمجتمعات، والتي تستهدف صقل الثخصية الثبابية

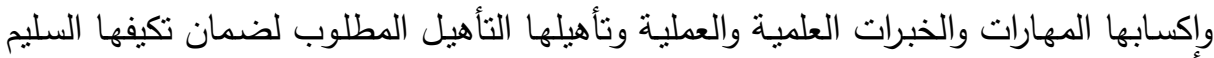
مع المستجدات، وكذلك وتدريب القادة الثباب في مختلف الميادين المجتمعية، لكن ما يجب ولهب

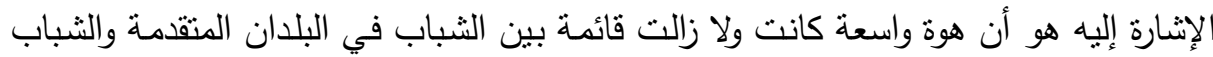

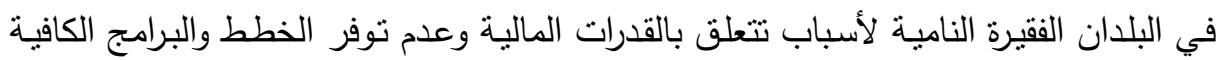

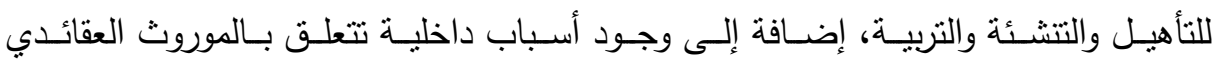

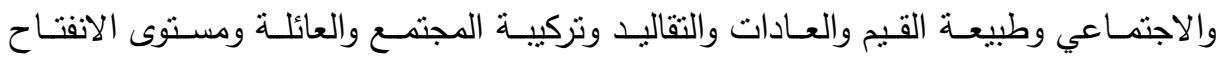
الاجتماعي وطبيعة النظم السياسية القائهـة؛ حيث تضـافرت كل تللك العوامل لتحد من دور

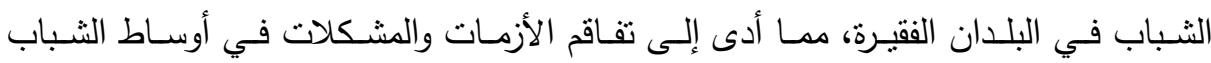
كالبطالة، وسوء العناية الصحية، وتدني المستوى المعيثي، ونقص المؤسسات الراعية ومراكز

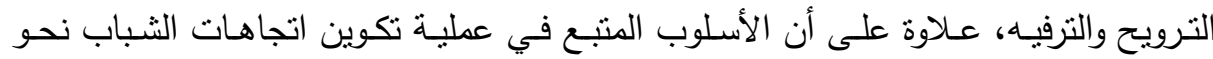
البيئة، ويجب أن يراعى فيه الأسلوب العلمي القائم على تحديد المشكلة ووضـع إستراتيجية علاجها (أو حلها) وتقويم مراحل هذه الأخيرة، وعدم وضوح المشاركة بسبب غياب الحكم الرشيد والديمقراطية.

وبنـاءًا على اطـلاع البـاحثنون على الدراسـات السـابقة، وتحليل المشكلات والمعوقات، ودراسة المقترحات ؛ فقد نم اعتبار هذا البحث استكمالا لما سبق من أبحاث في ذلك المجال

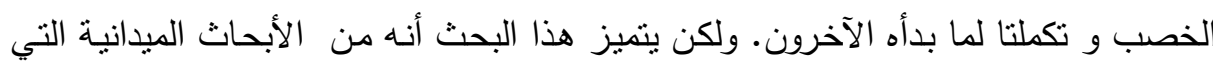

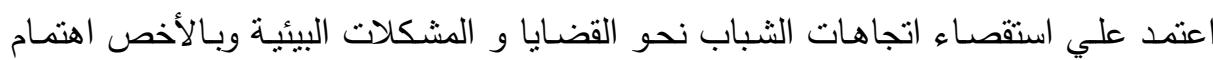
الثباب بالتعامل مـع التغيرات البيئية في مجتمعاتهم المحلية و ومشاركتهم في مجابهة وحل القضايا البيئية الخاصة بمجتمعهم المحلي وأهمية إيجاد طرق لإثراكهم في العمل البيئي منذ

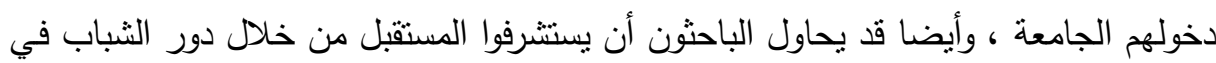
تتمية المجتمع المحلي. 


\section{أهمية الصراسلة}

ا الأهميـة العلميـة: دراسـة القضـايا البيئية التي تواجه المجتـع، والتعرف على اتجاهـات

الثباب نحو نلك القضايا وانعكاساتها على تتمية المجتمع المحلي.

r الأهميـة التطبيقيـة: في ضوء ما نوصل إليه الباحثون من نتائج يمكن وضـع سياسـة اجتماعية رشيدة للحد من المعوقات التي تحد من دور الثباب في نتمية المجنمع المحلي

بيئيًا.

r م الجهات المستفيدة: في ضوء ما توصل إليه الباحثون من نتائج يمكن أن يكون هناك عدد لا بأس به من الجهات المستفيدة من هذا البحث مثل متخذي القرار والمسئولين عن الثباب الجامعي وإثراكهم في حماية البيئة والمساعدة في إيجاد حلول للمشكلات والقضايا البيئية التي تواجه مجنمعهم المحلي مثل وزارة التعليم العالي والجامعات المصرية وجهاز شئون البيئة، ومؤسسات المجتمع المدني المصرية والعالمية .

\section{أهساهي الصواسمة}

تعتمد الدارسة الحالية على عدة أهداف تسعي إلى تحقيقها، هي: أ- تحديد المعارف والمعلومات البيئية لدي الثباب الجامعي، ومصادر الحصول علئه عليها.

ب- تحديد اتجاهات الثباب الجامعي نحو النهوض بالبيئية.

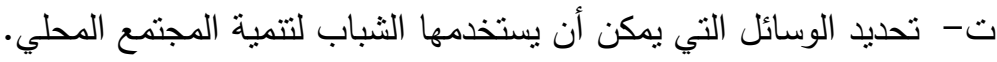
ث- تحديد المشكلات التي تعوق الثباب نحو النهوض بالبيئة.

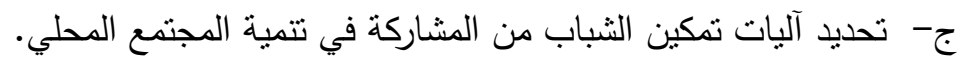
ح- تحديد دلالة المشاركة الثبابية في التتمية البيئة. خ- وضع سياسة اجتماعية رشيدة لتتمية المجتمع المحلي بيئًًا. 


\section{مهناهيور السراسمة}

1-مفهوم الاتجاهات البيئية: وتقصد بـه الباحثة "الموقف الذي يتخذه الثباب الجامعي نحو البيئة، وحمايتها من المخاطر التي تتعرض لها، والحفاظ على مواردها بشكل مستديم،

$$
\text { وموقفه نحو تحقيق تتمية المجتمع". }
$$

r-مفهوم الثباب الجامعي: وتحددهم الباحثة بأنهم "هم الذين يقعون في الفئة العمرية ما بين

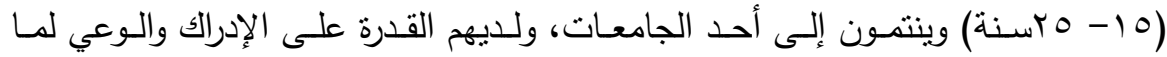

$$
\text { حولهم، ولديهم علامات النضج الاجتماعي والبيولوجي". }
$$

r-مفهوم القضايا البيئة: وتثشير إليها الباحثة بأنها " تلك القضايا التي تؤثثر بالسلب على هلى

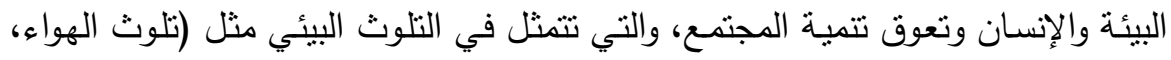
تلوث المياه، تلوث سطح الأرض)، واستتزاف الموارد مثل (استتزاف المياه، استنزاف الثروة

$$
\text { النباتية، استنزاف الثروة الحيوانية، استنزاف التربة)". }
$$

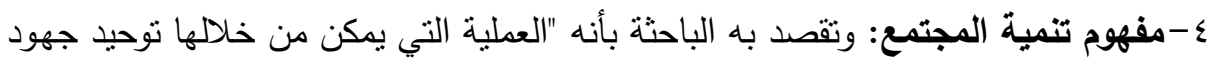

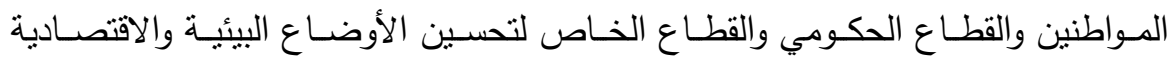

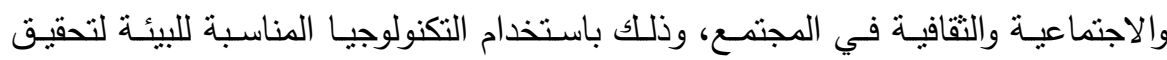
التوازن البيئي والحفاظ على الموارد الطبيعية".

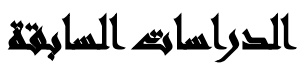

يمثل عرض الدراسات السابقة أهمية بالنسبة لهذه الدراسة؛ حيث تكثف عن الأبعاد التي

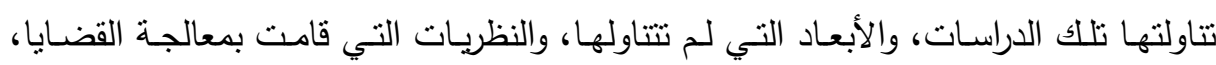

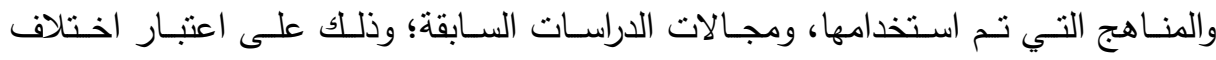
الظواهر ، والمشكلات باختلاف السياقات الزمنية، والمكانية، والبشرية.

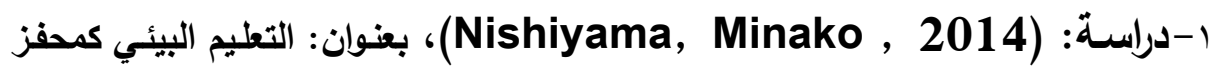
للتغيير في المواقف البيئية للطلاب، وقد استهدفت هذه الدراسة النعرف على التعليم البيئي كمحفز للتغيير في المواقف البيئية للطلاب، وقد تم مسح للعشر جامعات في مناطق خليج 
طوكيو وخليج سان فرانسيسكو، وقد أوضـح الباحث أن التربية البيئية المعترف بها دوليًا

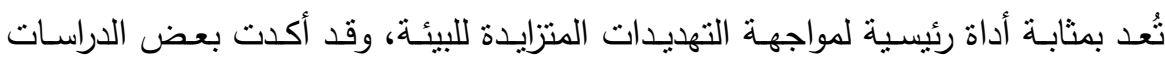

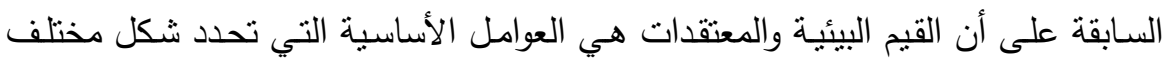

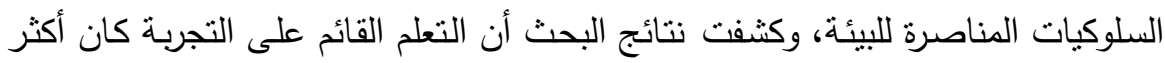

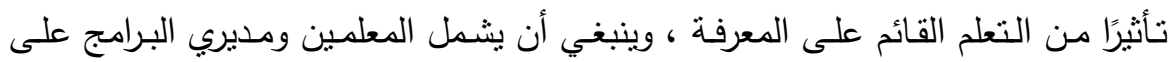
المزيد من النهج التعليمي القائم على الخبرة في التعليم البيئي، وينبغي التأكيد على أهمية التئي عملية التعليم البيئي مدى الحياة. ץ-دراسـة: ( Singletary, Joanna Lynn Bush , 2013 )، بغوان: دور خدمة التعلم في مجال محو الأمية البيئية لطلاب الجامعات، واستهدفت هذه الدراسة

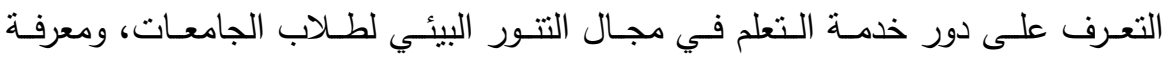
المحتوى، والاتجاهـات، والسـلوكيات، فهذه الدراسـة تقيم العلاقـة بين خدمـة التعلم البيئي على محو الأمية البيئية في الجامعيين، وقد استتنج الباحث أن الطلاب الذين شاركوا في

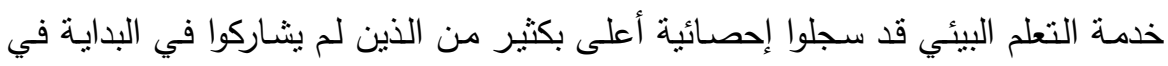

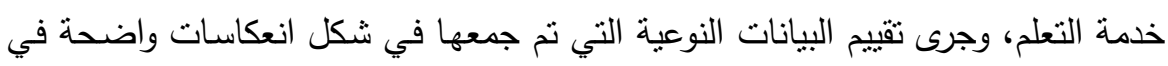
الحفاظ عن المظاهر والمواقف البيئية أو بيانات عن السلوكيات والمهارات الإيجابية للبيئة،

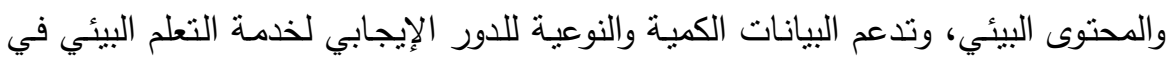
تتمية الوعي البيئي لاى الطلاب الجامعيين. r-دراسة: (Laura Wray-Lake, 2010)، بعنوان: اتجاهات وسلوكيات الطلاب البيئية، ونقدم هذه الدراسة تحليلاً وصفيًا للاتجاهات البيئية، والمعتقدات، والسلوكيات في بلهوات،

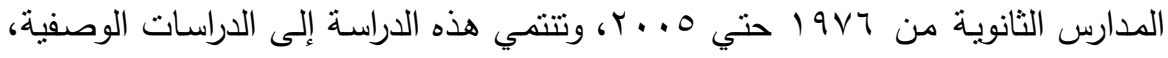
وتوصلت هذه الدراسة إلي عدة نتائج تكثف عن أن الثباب يميلون إلى إسناد المسئولية

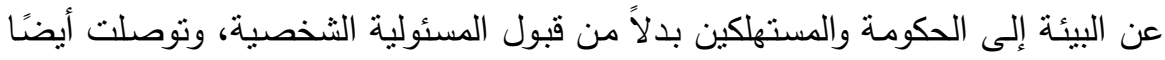
إلي تراجع الاهنمامات البيئية لدي عينة الدراسة من الثباب، وتتشير النتائج إلي ضرورة الاهتمام بوجهات نظر الثباب والدعوة إلى تربية بيئية وقيادة حكومية أفضل.

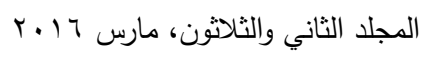


ع-دراسـة: ( Bostic, Nina Crawford , 2008 ( بغنوان: المعارف والاتجاهات والسلوكيات من طلاب الجامعات في علوم الأسرة والمستهلك نحو الملابس صديقة للبيئة، وقد استهدفت هذه الدراسة التعرف على المعارف والاتجاهات والسلوكيات من طلاب الجامعات في علوم الأسرة والمستهلك نحو الملابس صديقة البيئة، وأن الغرض لهابل من هذه الدراسة هو تحديد الاتجاهات والمعارف، والسلوكيات من طلاب الجامعات نحو الملابس صديقة البيئة، ودراسة وجود علاقة بين العمر فيما يتعلق بالمعارف والاتجاهات والسلوكيات، ودراسـة الفرق بين مكان ميلاد الطالب في ما يخص المعرفة والاتجاهات والسلوكيات، ودراسة الاختلافات في المعرفة والاتجاهات والسلوكيات بين التخصصات. ه-دراسة: (هانم محمد مصطفى، V . . . P)، بعنوان: أثر التدعيم الإيجابي على تحفيز

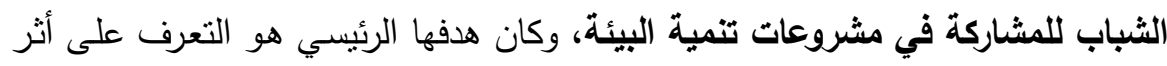

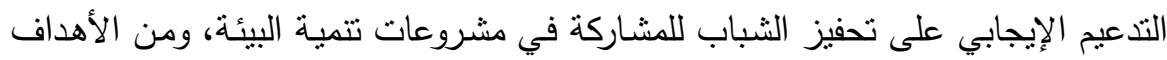
أيضًا توضيح الأدوار التي يمكن أن يقوم بها الثباب ومردودهـا الإيجابي علي البيئة،

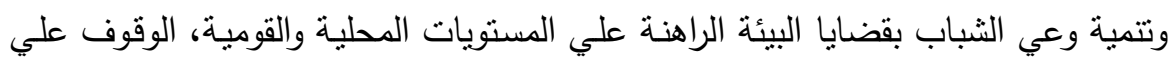

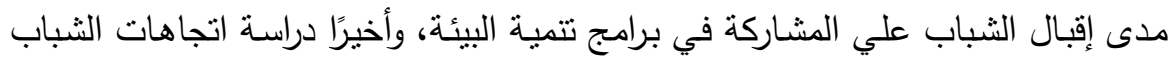

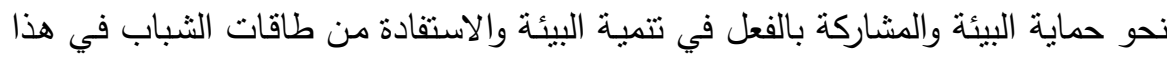
المجال، توصلت الباحثة أن التتمية تحتاج من المواطنين التطوع بمجهودهم لتحسين البيئة

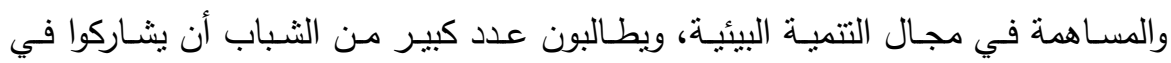
مشاريع التتمية البيئية بتقدير جهوده باستلام الجوائز العينية والمادية وشهادات التقدير . צ- دراسة: (مجدي فاوي أبو العلا، ه • . †)، بعنوان: المعكرات كأداة في خدمة الجماعة لتمية المجتمع المحلي (دراسة تحليلية لمشروع اخدم بلدك)، واستهدفت الدراسة

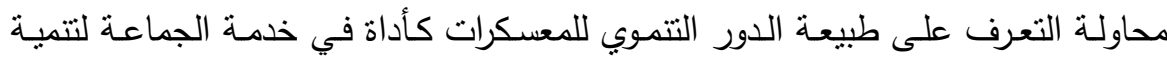
المجتمع المحلى، ومحاولة التعرف على الفوائد التي تعود على الثباب من خلال اشتراكهم

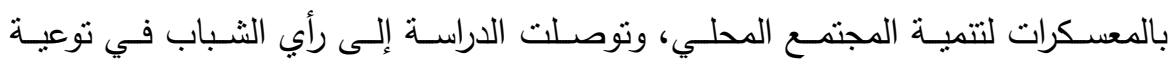


الخدمات البيئية التي قدمها برنامج المعسكر لتتمية مجتمعه حيث أن الغالبية العظمى من الثباب يرون أن برنامج المعسكر قدم خدمات بيئية بدرجة كبيرة.

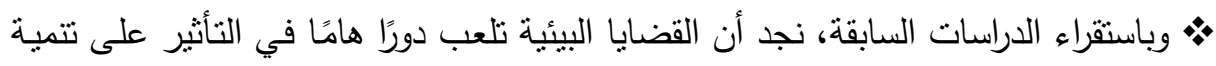

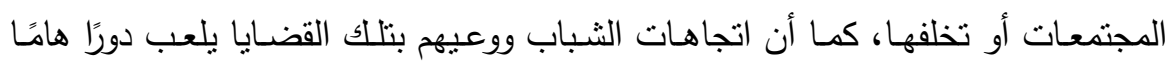
أيضًا تجاه تلك القضايا والمحافظة على البيئة، ومدى نأثثير ذلك على نتمية المجتمع، كما لتهات

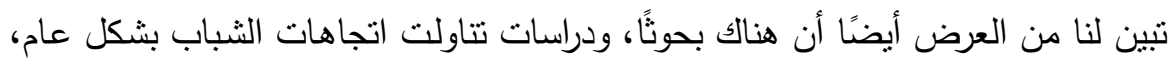

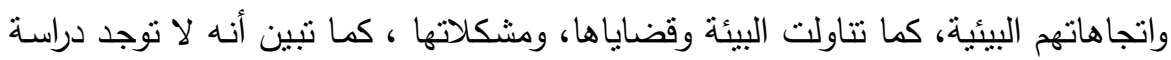

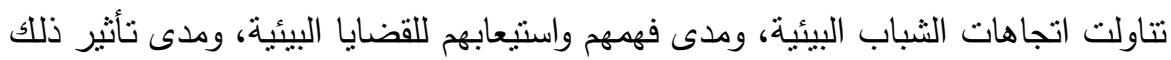
على تتميـة المجتمع المحلى، ومن ثم تتمية المجتمع ككل، والمحافظة عليه وعلى البيئة

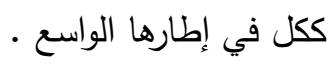

\section{الإجباءاهي المنمجية للقرواسة}

نوع الدراسةة: تتنثي هذه الدراسة إلى الدراسات الوصفية التحليلية. منهج الدراسة: تعتمد الدراسة على منهج المسح الاجتماعي بالعينة. أدوات الاراسةة: اعتمد الباحثون على استمارة استبانة للشباب الجامعي من إعداد الباحثين. وصـف اسـتمارة الاسـتبيان: حيث قام البـاحثون عند تصميم الاستمارة بمجموعـة مـن

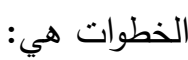
1- الاطلاع على الدراسات والبحوث السابقة، والكتابات النظرية، التي اهتمت بالثباب بشكل عام والثباب الجامعي بشكل خاص. r- تحديد البيانات الأولية لعينة الدراسة، والتي اشتملت على (الاستم "اختياري"، النوع، العمر ،

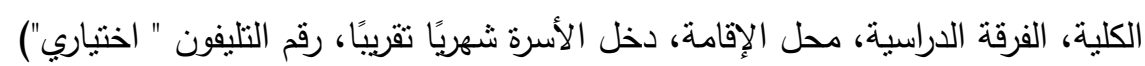

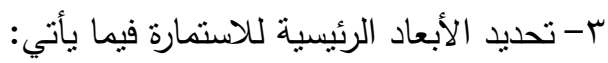

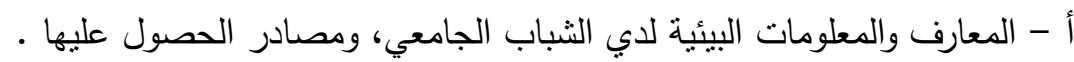
ب - اتجاهات الثباب الجامعي نحو النهوض بالبيئية .

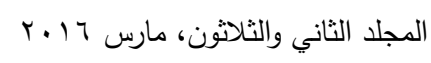


ج - الوسائل التي يمكن أن يستخدمها الثباب لتتمية المجتمع المحلي، وهي تلك الأدوات التي يمكن أن تساعد الثباب في نشر الوعي البيئي وتتمية المجتمع المحلي.

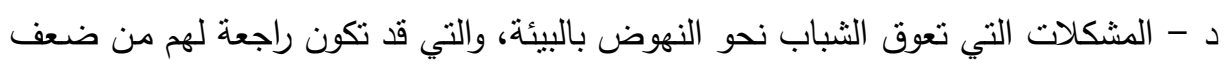

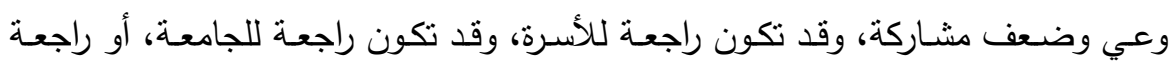

$$
\text { للاولة. }
$$

هـ - آليات تمكين الثباب من المشاركة في تتمية المجتمع المحلي .

و - دلالة المشاركة الثبابية في التتمية البيئة .

ز - صياغة العبارات الدالة على كل مؤشر من الأسئلة السابقة. وقد راع الباحثّن في تصميم الاستمارة ما يأتي:

أ- تحديد نوع البيانات الواجب الحصول لون عليها. ب-وضع الأسئلة التي ترتبط ارتباطًا وثيقًا بهدف الدراسة أبها.

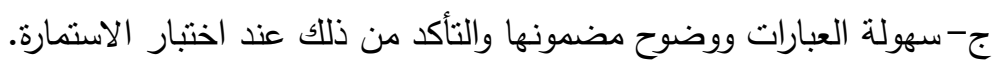
د- نَّاسْبُبُ الأسئلة مع المستوبي التعليمي والثقافي للثباب الجامعي. الصدق والثبات: - (الثرات

1- الصدق: استخدم الباحثون نوعين من الصدق وهما: أ - الصدق الظاهي: وهو يتضمن نسب اتفاق المحكين على أسئلة الاستمارة، حيث تم

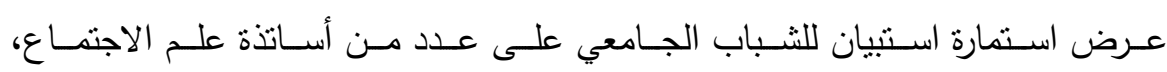

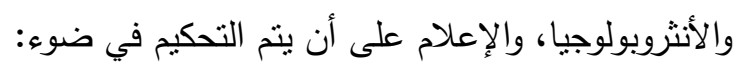
ا ا. مدى ارتباط العبارة بكل بعد من أبعاد الدراسة.

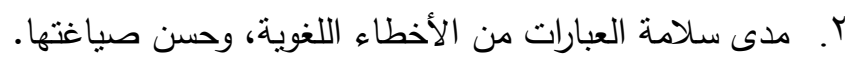
r. مدى شمولية العبارات على مضمون الدراسة. 
وبناءًا على ذلك فقد تم تعديل الأبعاد العامـة للاستمارة، وتم حذف العبارات التي تقل نسبة الاتفاق عليها عن •^\% من قبل السادة المحكمين، وقد تم حساب نسبة الاتفاق وفقًا

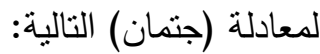

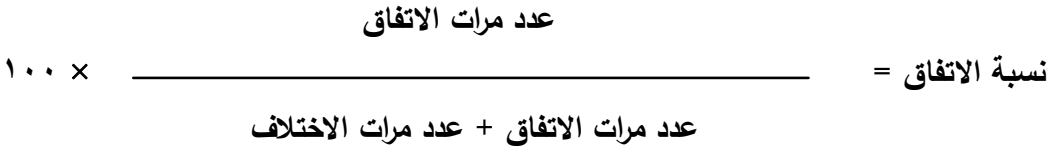
• وقد نم تعديل بعض العبارات بموافقة السادة المشرفين على الدراسة. ب- الصدق الإحصائسي: حيث تم حساب الصدق الإحصائي بأخذ الجذر التربيعي لمعامل ثبات الاستمارة، وعليه

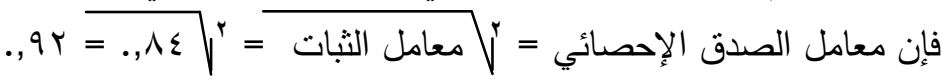
وقد استفادت الباحثة من إجراء عمليتي الصدق "الظاهري، والإحصائي" في إلغاء بعض الأسئلة، وإعادة صياغة بعضها الآخر بما يتلاعم مع أهداف الدراسة. r - الثبـات: قامت الباحثة بحسـاب معامل ثبات الاستمارة، باستخدام طريقة إعادة الاختبار Test-Retest حيث تم تطبيق الاستمارة على عينة عشوائية قوامها (.0) شاب وفتاة من مجتمـع مشـابه لمجتمع الدراسـة، وبعد ذلك تم إعـادة تطبيقها على نفس العينة بعد فاصل زمني (10) يوم، أي بواقع أسبوعين بين التطبيق الأول والثاني، وقد قامت الباحثة باستبعاد البيانات الأولية، والأسئلة المفتوحة عند إجراء الثبات، وتم استخدام معامل ارتباط بيرسون، لقياس درجة الارتباط بين التطبيق الأول والثاني.

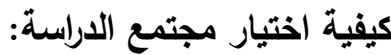
ا. المستوي الأول: يتمثل في اختيار الكليات: حيث تم اختيار (Y) كلية من ضمن كليات جامعة عين شمس تمتل الجانبين النظري والعملي وهما (كلية الآداب، كلية العلوم). r. المستوي الثاني: يتمثل في اختيار عينة الدراسة من الثباب الجامعي: من بين الكليتين،

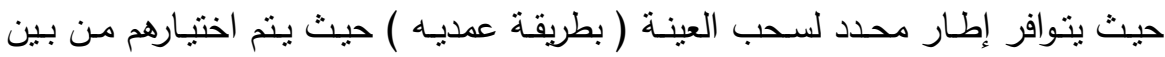


المقيدين بالكليـة، على أن يكونـوا مقيدين ضمن جماعـة الخدمـة العامـة والجوالـة برعايـة الثباب بالكلية، وأن يكون لديهم الاستعداد لنطبيق الاستمارة بها.

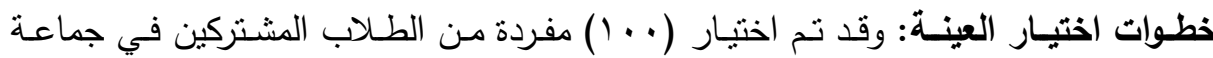
الخدمة العامة والجوالة في كل كلية، وذلك لأنهم فعلاً يمارسون في كافة الأنشطة التي تُعدها

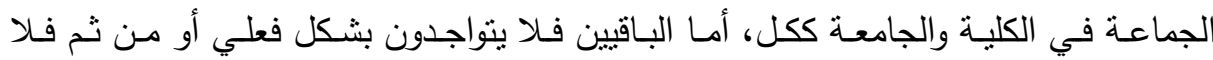

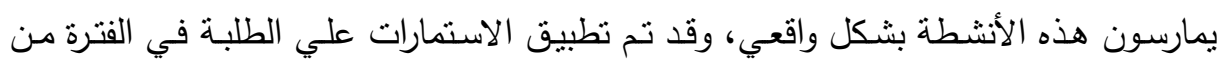

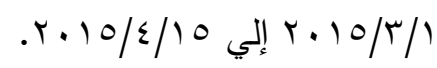

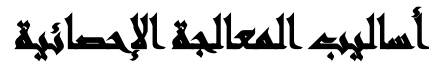

استخدمت الباحثة مجموعة من الأساليب الإحصائية المناسبة لتحليل البيانات والتي تتفق مع طبيعة تلك البيانات وذلك باستخدام برنامج (SPSS) لحساب (التكرارات والنسب المئوية،

.(Chi-Square Tests

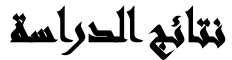

جدول رقـم(1): يوضـح الفروق بين الكليـات فيمـا يتعلـق بمدى توعيتهم لزملائهم بأهميـة المشاركة في المشروعات البيئية

\begin{tabular}{|c|c|c|c|c|c|c|c|}
\hline \multicolumn{2}{|c|}{ إجمالى } & \multicolumn{2}{|c|}{ عملية } & \multicolumn{2}{|c|}{ نظرية } & \multirow{2}{*}{ الاستجابة } & \multirow[b]{2}{*}{ p } \\
\hline$\%$ & ك & $\%$ & ك & $\%$ & ك & & \\
\hline$\varepsilon \Lambda$ & 97 & $r \cdot, 0$ & $\sum 1$ & $\overline{T V, 0}$ & 00 & 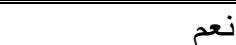 & .1 \\
\hline Or & $1 \cdot \varepsilon$ & $r 9,0$ & 09 & Yr,O & $\leqslant 0$ & $\gamma$ &.$Y$ \\
\hline $1 \ldots$ & $r \ldots$ & 0. & $1 \ldots$ & 0. & $1 \ldots$ & الإجمالي & \\
\hline
\end{tabular}

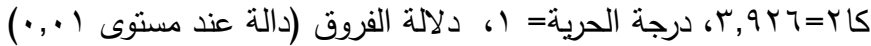

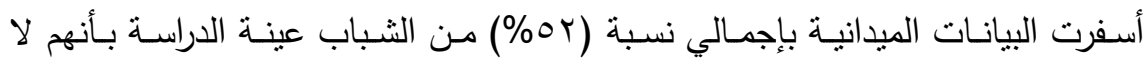

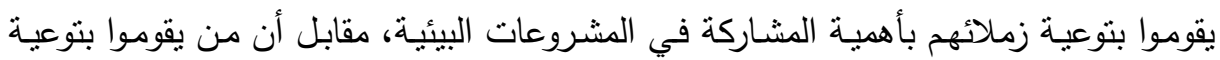

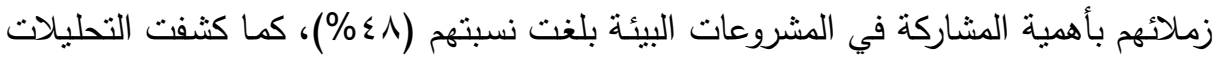
الإحصائية وجود فروق ذات دلال إحصائية بين الكليات النظرية والعملية عند مستوى معنوية 
علي محمود أبو ليلة وآخرون

(1 , , ) فيما يتعلق بتوعية الثباب الجامعي لباقي زملائهم على المشاركة في المشروعات

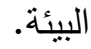

جدول رقم(ץ): يوضـح الفروق بين الكليات فيما يتعلق بمدى محاولتهم لتقديم حلول بديلة لمواجهة المشكلات البيئية

\begin{tabular}{|c|c|c|c|c|c|c|c|}
\hline \multicolumn{2}{|c|}{ إجمالى } & \multicolumn{2}{|c|}{ عملية } & \multicolumn{2}{|c|}{ نظرية } & \multirow{2}{*}{ الاستجابة } & \multirow[b]{2}{*}{ b } \\
\hline$\%$ & ك & $\%$ & ك & $\%$ & ك & & \\
\hline OV & $11 \varepsilon$ & $\mu$. & 7. & TV & $0 \leqslant$ & 20 &.$\Gamma$ \\
\hline$\varepsilon \mu$ & $\Lambda 7$ & $r$. & $\varepsilon$. & Tr & $\sum 7$ & $y$ &.$\varepsilon$ \\
\hline $1 \ldots$ & Y.. & 0. & $\ldots$ & 0. & $1 \ldots$ & الإجمالى & \\
\hline
\end{tabular}

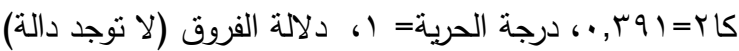

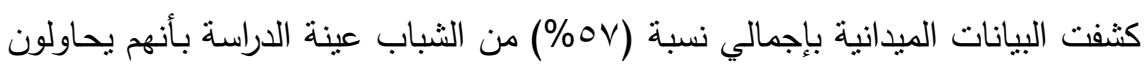

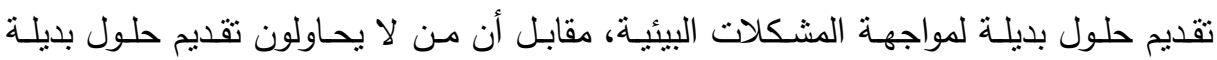

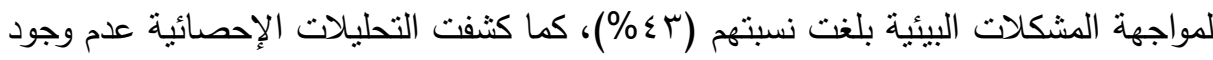
فروق ذات دلال إحصائية بين الكليات النظرية والعملية فيما يتعلق بمحاولة الثباب الجامعي التهابي تقديم حلول بديلة لمواجهة المشكلات البيئية. جدول رقم(؟): يوضـح دلالة المشاركة الثبابية في إحداث التميـة البيئية حسب نوع الكلية (نظرية- عملية)

\begin{tabular}{|c|c|c|c|c|c|c|c|}
\hline \multicolumn{2}{|c|}{ إجمالى } & \multicolumn{2}{|c|}{ عملية } & \multicolumn{2}{|c|}{ نظريـة } & \multirow{2}{*}{ الاستجابة } & \multirow[b]{2}{*}{ b } \\
\hline$\%$ & ك5 & $\%$ & ك5 & $\%$ & ك & & \\
\hline $9 \wedge$ & 197 & $\leqslant 9$ & 91 & $\leqslant 9$ & 91 & شَارع بالحي صناديق للقمامـة والمخلفات في كل & \\
\hline $9 \wedge$ & 197 & $\leqslant 9$ & 91 & $\leqslant 9$ & 91 & ألمخصصـة القمانـــة والمخلفــات فـي الأمــاكن &.$r$ \\
\hline AT & $1 \mathrm{WI}$ & $\sum \mu$ & 入т & $\varepsilon \Gamma$ & 10 & تشغيل المسجلات بصوت منخفض &.$r$ \\
\hline NT & $17 \varepsilon$ & ६. & $\sqrt{99}$ & $\varepsilon \Gamma$ & 10 & استخدام آلات تتبيه السبارات عند الضرورة & . \\
\hline $9 \mu$ & 1117 & $\leqslant 0$ & 9 . & $\sum \wedge$ & 97 & عدم حرق المخلفات والقمامة في الثارع & .0 \\
\hline $9 \mu$ & 1117 & $\leqslant 9$ & $9 \mathrm{~V}$ & $\leqslant 0$ & 19 & تدوير المخلفات بشكل مفيد وآمن & .7 \\
\hline 9) & IAY & $\leqslant 7$ & 94 & $\leqslant 0$ & 9 . & الترشيد في استخدام المياه &.$v$ \\
\hline 9. & in. & $\leqslant 7$ & 94 & $\varepsilon \varepsilon$ & $\Lambda \wedge$ & الترشيد في استخداح إنارة الثوارع &.$\Lambda$ \\
\hline 94 & $1 \wedge \varepsilon$ & $\sum V$ & 9 9 & $\leqslant 0$ & 9. & ترشيد استهلالك الطاقة بالمنازل & .9 \\
\hline
\end{tabular}


أظهرت بيانـات الجدول السـابق، المتعلق بدلالمة المشـاركة الثبابية في إحداث التتميـة البيئية، وذلك من وجهة نظر عينة الدراسـة، أن الثباب في الكليات النظرية والعملية تساووا

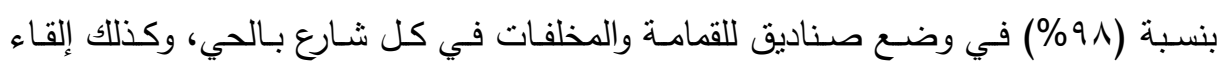

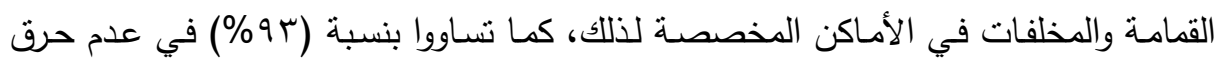

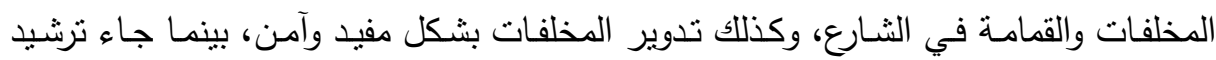

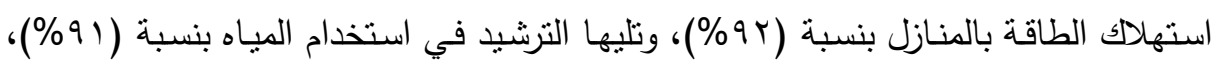

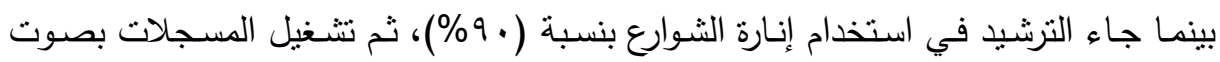

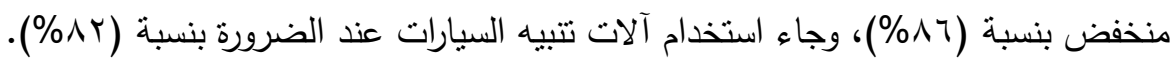

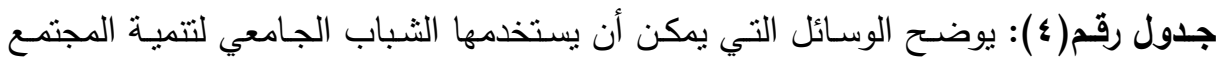
المحلي حسب نوع الكلية

\begin{tabular}{|c|c|c|c|c|c|c|c|}
\hline \multicolumn{2}{|c|}{ إجمالى } & \multicolumn{2}{|c|}{ عملية } & \multicolumn{2}{|c|}{ نظريـة } & \multirow{2}{*}{ الاستجابة } & \multirow[b]{2}{*}{ r } \\
\hline$\%$ & ك & $\%$ & t & $\%$ & ك & & \\
\hline 19 & $\operatorname{lvA}$ & $\leqslant \varepsilon$ & $\Lambda \Lambda$ & «0 & 9 . & 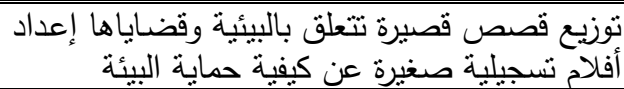 & .1 \\
\hline 9 . & $1 \wedge$. & 乞0 & 9. & $\leqslant 0$ & 9 . & 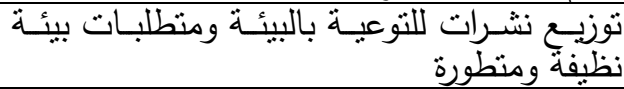 & .r \\
\hline ᄉᄉ & 180 & $\varepsilon \Gamma$ & 10 & $\leqslant 0$ & 9 . & نشر مقالات على الانترنت من أجل بيئة أفضل & .r \\
\hline NT & 170 & $\sum Y$ & $\Lambda \varepsilon$ & 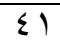 & Al & عقد ندوات نوعية عن المشكلات البيئية & ـ \\
\hline$v_{7}$ & $10 r$ & « & NT & ro & $v \cdot$ & ألبيئة إدلة أفلام تسجيلية صـغيرة عن كيفيـة حمايـة & .0 \\
\hline 90 & 19. & $\sum v$ & $9 \varepsilon$ & $\sum \Lambda$ & 97 & تتفيذ حملة نظافة بالحي & .7 \\
\hline $9 \varepsilon$ & 111 & $\varepsilon V$ & $9 \mu$ & $\varepsilon \Lambda$ & 90 & تتفيذ حملة لتوعية المواطنين بمخاطر التلوث &.$v$ \\
\hline $9 \varepsilon$ & 111 & $\sum V$ & 94 & $\leqslant \Lambda$ & 90 & تتفيذ مشروعات تشجير المجتمع المحلى &.$\wedge$ \\
\hline AT & $17 \pi$ & $\varepsilon$. & $\Lambda$. & $\varepsilon Y$ & $\Lambda T$ & إقامة معسكر اليوم الواحد لتجميل الحي & .9 \\
\hline
\end{tabular}

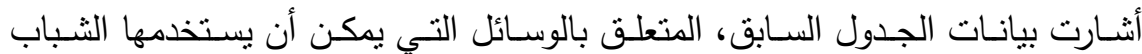

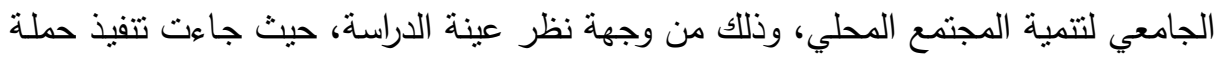
نظافة بـالحي بنسبة (90\%)، بينما تسـاوى كل من تتفيذ حملـة لتوعيـة المواطنين بمخـاطر

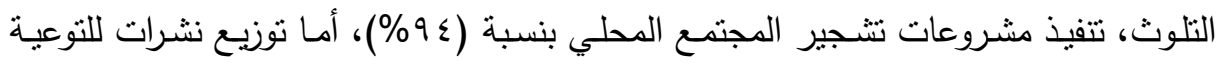

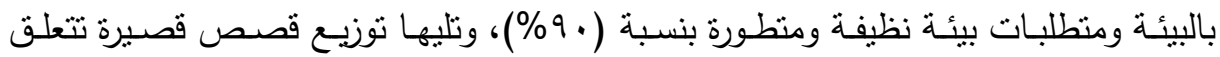


بالبيئية وقضاياها إعداد أفلام تسجيلية صغيرة عن كيفية حماية البيئة بنسبة (9^\%)، ثم جاء

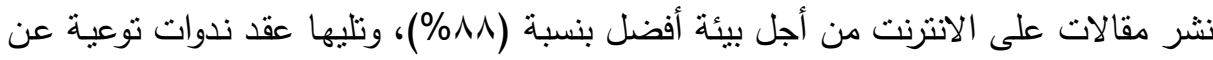
المشكلات البيئية بنسبة (r^\%)، كما جاءت إقامة معسكر اليوم الواحد لتجميل الحي بنسبة

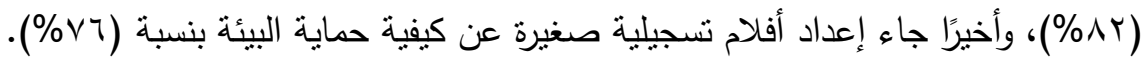
جلول رقم(ه): يوضح المشكلات الني تعوق الثباب الجامعي نحو النهوض بالبيئة حسب نوع بله الكلية

\begin{tabular}{|c|c|c|c|c|c|c|c|}
\hline \multicolumn{2}{|c|}{ إجمالى } & \multicolumn{2}{|c|}{ عملية } & \multicolumn{2}{|c|}{ نظرية } & \multirow{2}{*}{ الاستجابة } & \multirow[b]{2}{*}{ b } \\
\hline$\%$ & s & $\%$ & 5 & $\%$ & S & & \\
\hline 97 & 191 & $\Sigma V$ & $\overline{9 \varepsilon}$ & $\sum 9$ & $9 \mathrm{~V}$ & ضعف وعى الثباب بالقضابا البيئية & .1 \\
\hline 91 & 190 & ะ9 & $9 \mathrm{~V}$ & $\sum 9$ & 91 & ضعف مشاركة الثباب في الأنشطة البيئية &. $\mathrm{r}$ \\
\hline $9 \mathrm{~V}$ & 195 & 0 . & $1 \cdots$ & $\leqslant \vee$ & $9 \varepsilon$ & 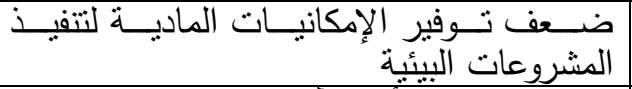 &.$r$ \\
\hline $9 \mathrm{~V}$ & 194 & $\leqslant 9$ & 91 & $\varepsilon \Lambda$ & 90 & ضعف اهتمام الأسرة بأهمية الحفاظ على البيئة & . \\
\hline $9 \vee$ & $19 \pi$ & $\sum \Lambda$ & 97 & $\leqslant 9$ & $9 v$ & المشكلات وعي ألبيئةراد المجتمـع المحلي بخطورة & .0 \\
\hline 97 & 191 & $\varepsilon \wedge$ & 97 & $\varepsilon \Lambda$ & 90 & 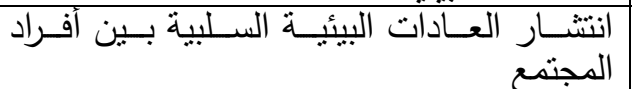 & .7 \\
\hline 9 & 110 & $\varepsilon \wedge$ & 90 & ¿0 & 9. & ضدنسف والجامعاونة البيئي بين مؤسسـات المجتهـع &.$v$ \\
\hline $9 \varepsilon$ & INV & $\leqslant\rceil$ & 94 & $\sum \Lambda$ & 90 & البيئية الإجراءات والروتين عند تتفيذ المشروعات &.$\wedge$ \\
\hline $9 \vee$ & 194 & 0 . & 99 & $\varepsilon V$ & $9 \varepsilon$ & الأنثـــة الأسيئية بالتحصـيل الدراسـي أكثر مـن & .9 \\
\hline
\end{tabular}

أسفرت بيانات الجدول السـابق، المتعلق بالمشكلات التي تعوق الثباب الجامعي نحو النهوض بالبيئة، وذلك من وجهة نظر عينة الدراسة؛ حيث جاء ضعف مشاركة الثباب في

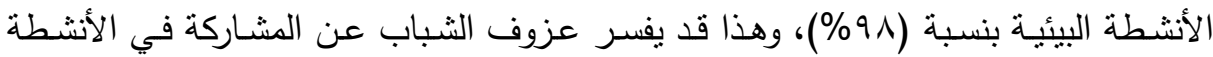

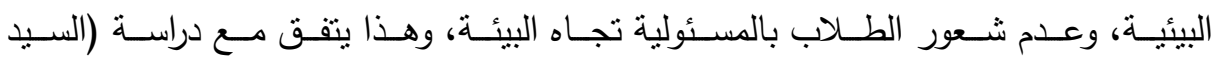

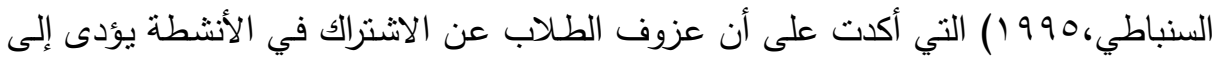

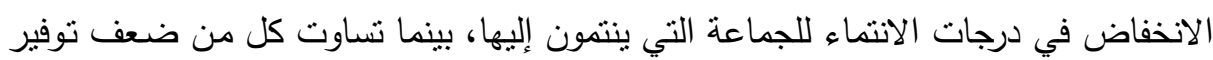

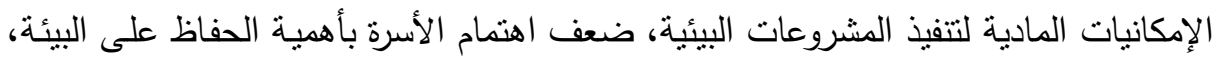

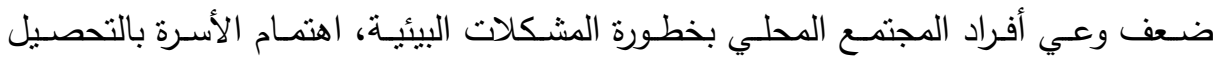

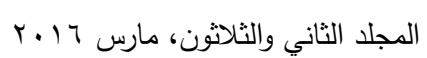


الدراسي أكثر من الأنشطة البيئية بنسبة (v9\%). ويتفق ذلك مع دراسة (عزت عرفة وعصام

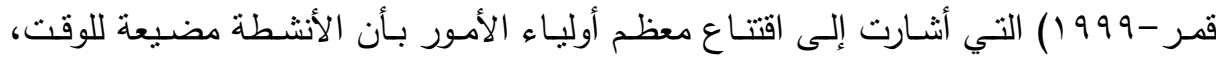
وتنساوت أيضًا كل من ضعف وعي الثباب بالقضايا البيئية، انتشـار العادات البيئية السلبية بين أفراد المجتمع بنسبة (79\%)، بينما جاءت تعقد الإجراءات والروتين عند تتفيذ المشروعات

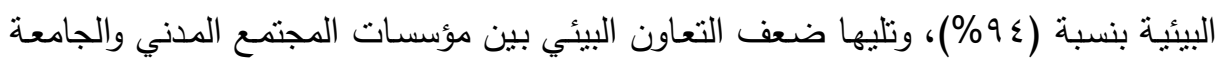
بنسبة (1\%). جدول رقم(7): يوضح آليات تمكين الثباب الجامعي من المشاركة في تتمية المجتمع المحلي

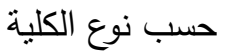

\begin{tabular}{|c|c|c|c|c|c|c|c|}
\hline \multicolumn{2}{|c|}{ إجمالى } & \multicolumn{2}{|c|}{ عملية } & \multicolumn{2}{|c|}{ ن نظرية } & \multirow{2}{*}{ الاستجابة } & \multirow[b]{2}{*}{ e } \\
\hline$\%$ & ك & $\%$ & ك & $\%$ & s & & \\
\hline $9 \wedge$ & 197 & $\leqslant 9$ & $9 \wedge$ & $\leqslant 9$ & $9 \wedge$ & 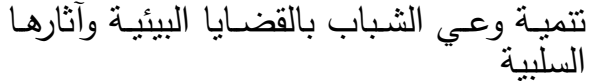 & .1 \\
\hline 91 & 197 & $\varepsilon 9$ & $9 \mathrm{~V}$ & 0. & 99 & تفعيل مشاركة الثباب في الأثشطة البيئية &. $\mathrm{r}$ \\
\hline 1.. & r.. & 0 . & 1.. & 0 . & $1 \cdots$ & تلبيئية الإمكانيـات الماديـة لتنفيذ المشـروعات & r \\
\hline 97 & 191 & $\varepsilon \Lambda$ & 90 & $\sum \Lambda$ & 97 & زيادة اهتمام الأسرة بأهمية الحفاظ على البيئة & . \\
\hline $9 \vee$ & 194 & $\varepsilon \wedge$ & 97 & $\leqslant 9$ & $9 \vee$ & 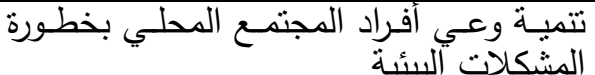 & .0 \\
\hline 91 & 111 & ¿0 & 9. & $\leqslant 7$ & 91 & زلزيـادة التعـاون البيئي بين مؤسسـات المجتمـع & .7 \\
\hline $9 \pi$ & 110 & $\leqslant 0$ & 9. & $\sum \Lambda$ & 90 & تسيئية الإجراءات والروتين لتنفيذ المشروعات &.$v$ \\
\hline 97 & 195 & $\varepsilon \Lambda$ & 97 & $\sum \Lambda$ & 97 & تبصير الأسرة بأهمية الانشطة البيئية &.$\wedge$ \\
\hline $9 \vee$ & $19 \varepsilon$ & $\leqslant \Lambda$ & 97 & $\leqslant 9$ & 91 & 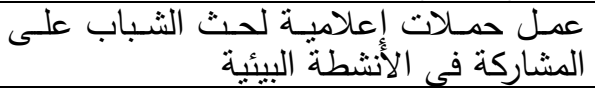 & .9 \\
\hline 91 & IAr & ¿0 & 9. & $\leqslant 7$ & 94 & تلعاوني القيادات المحلية في تتفيذ المشروعات & \\
\hline
\end{tabular}

أوضحت بيانات الجدول السابق، المتعلق بآليات تمكين الثباب الجامعي من المشاركة في تتمية المجتمع المحلي، وذلك من وجهة نظر عينة الدراسة، حيث جاءت توفير الإمكانيات

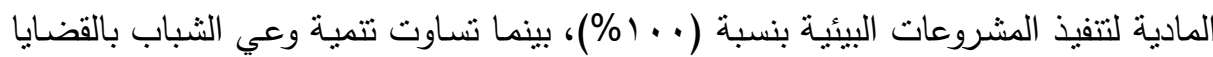

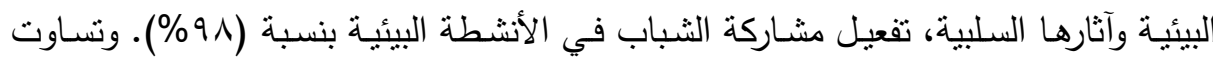


أيضًا تتمية وعي أفراد المجتمع المحلي بخطورة المشكلات البيئية، عمل حملات إعلامية لحث

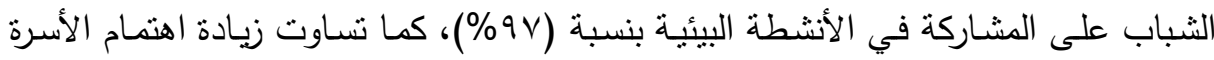

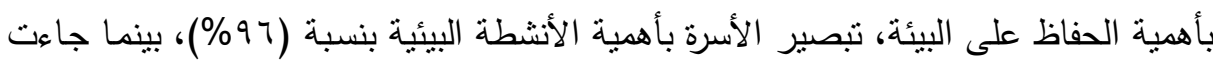

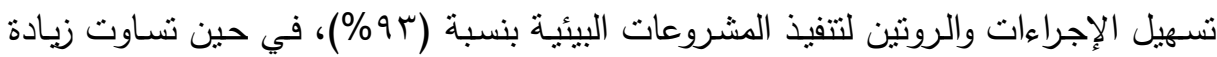

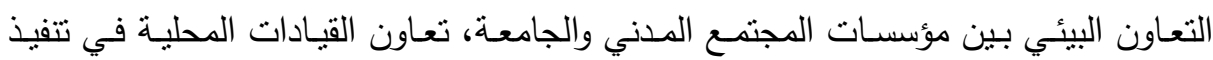
المشروعات البيئية بنسبة (19\%).

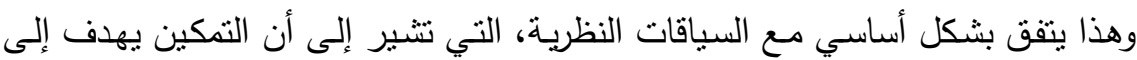

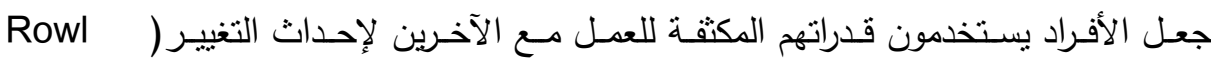

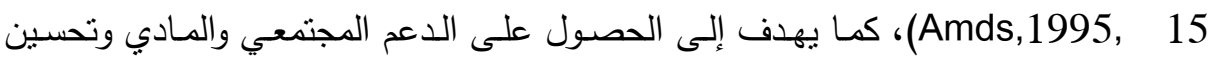

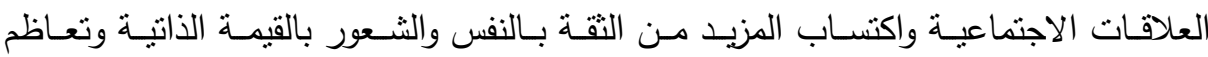
الاستقلالية ومواجهة الظروف الصـبة وتطور القدرات الجسيمة وتكوين الوعي والمشـاركة والمزيد من الفهم والإدراك والتخلص من عدم المساواة والتمبيز ووقف العنف وتحسين مستوي

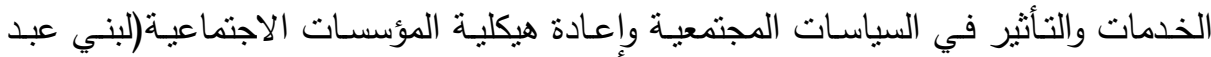

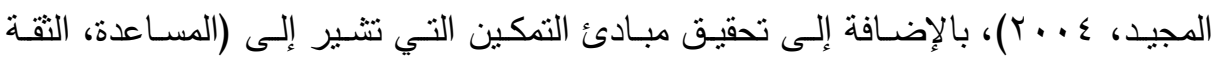

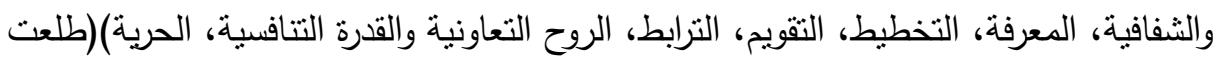

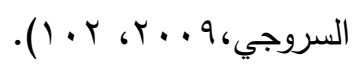

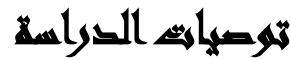

حاول الباحثون وضع مجموعة من الإجراءات التي تسهم بشكل أساسي في الارتقاء بييئة

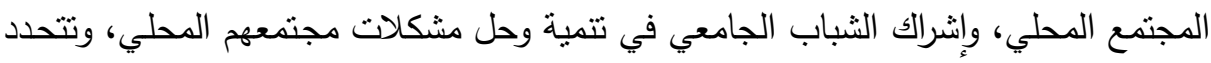
تلك الإجراءات في: 1- تشكيل مجلس أعلى للبيئة بكل مجتمع محلي. r- تعاون رجال الأعمال مع الجامعة؛ لدعم المشروعات البيئية. r- تعاون الجامعة مع مؤسسات المجتمع المحلي، بما يخدم البيئة المحيطة بهـ. 
ع- تنبى المجتمع المحلي لنقافة المصلحة العامة فوق المصلحة الخاصة.

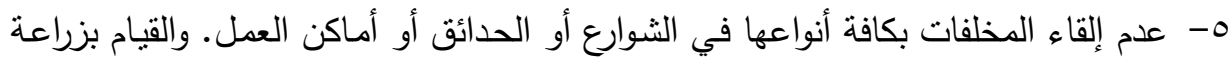
الأشجار والنباتات في كافة الأماكن الممكنة.

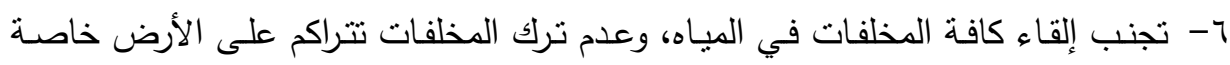

$$
\text { الزيوت وما شابهها. }
$$

V- الردم الصحي للمخلفات واختيار أنسب الأماكن لذلك، والاستفادة من المخلفات الصلبة وتحويلها إلى سماد عضدوي، وضـرورة العمل على فصل المخلفات الصلبة البلديـة من الصن

$$
\text { المنبع. }
$$

^- حل مشكلة القمامـة حلاً جذريًا على أن يؤخذ في الاعتبار : إن القمامة ليست نفايات يتم

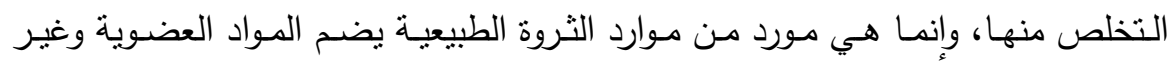

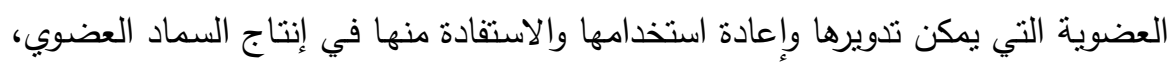
وإعادة تدوير الورق، والبلاستيك، والمعادن، والقماش، كما يمكن استخدام بعضها كمصدر

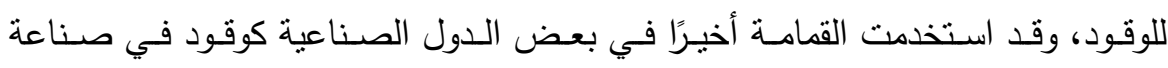

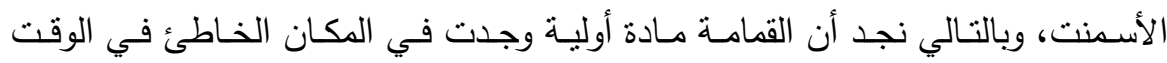
الخاطئ، ويمكن الاستفادة منها بوضعها في المكان المناسب في الوقت المناسب.

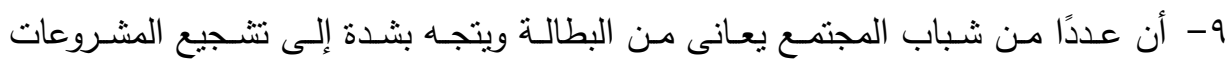

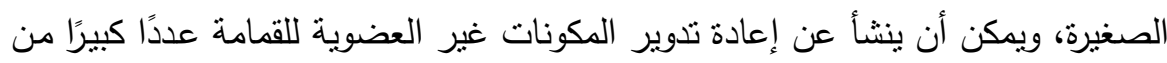
المشروعات الصغيرة غير الملوثة في المدن والقرى من خلال الجامعات المصرية.

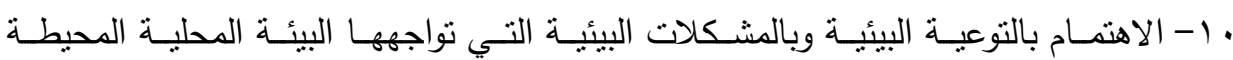
بالجامعات بما تحقق التوعية بين مجتمع الطلاب. 1 ا-تتمية شعورهم بالمسئولية تجاه المحافظة على البيئة ، تدريبهم على العمل الجماعي في

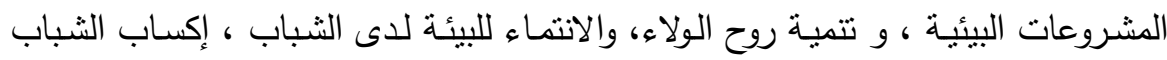
اتجاهات المواطنة الصالحة، وقيمها. 
r ا تشجيع الثباب على المشاركة في مشروعات الخدمة العامة ، تدريب الثباب على أعمال الصيانة، والنظافة، من خلال مشروعات الخدمة العامة و تعليمهم كيفية استغلال قدراتهم في الأنشطة البيئية .

با - تعميق القيم الدينية، والخلقية في نفوس الثباب منل (التعاون - عدم الفساد في الأرض).

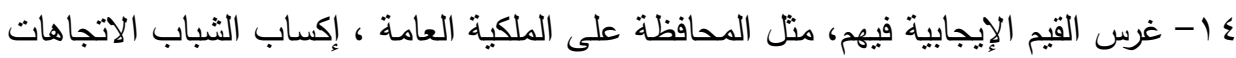

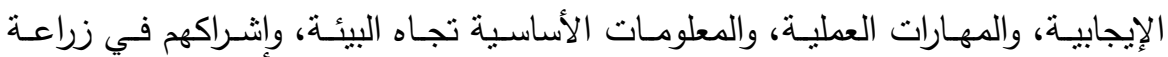

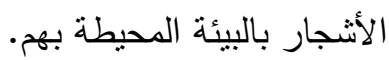
10 - تحديد أسبوع من كل عام لخدمة البيئة، وليكن تحت شعار " نحو بيئة نظيفة " بخرج فيه

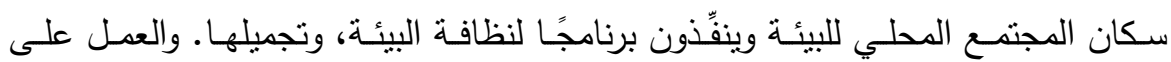

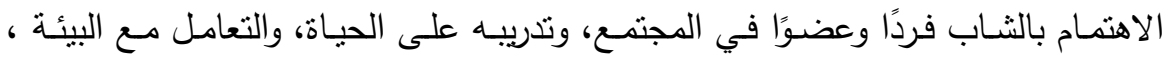
أهمية إكساب الثباب قيم الانتماء البيئي، من أجل تحقيق الحفاظ على البيئة بشكل عام الثبام في المستقبل.

17 - نشـر الوعي بقضـايا البيئة والصـحة والسكان لتصبح جزيءًا لا يتجزأ مـن التقافـة العامـة

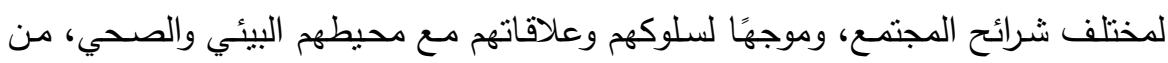

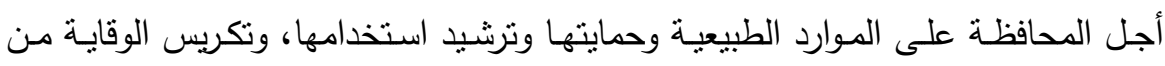
الأمراض والأوبئة والتعامل الحكيم والمتبصر مع قضايا تنظيم النسل.

\section{المرالئ}

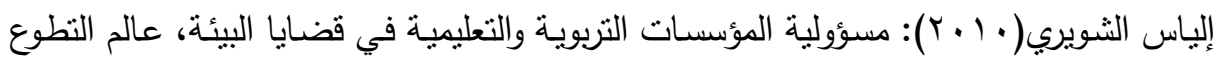
العربي، الأندية المجتمعية والسكانية، نادي البيئة التبية التطوعي.

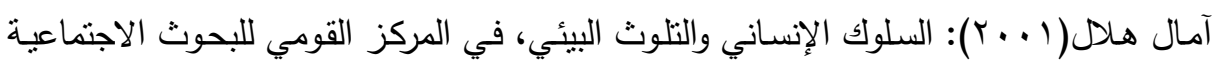

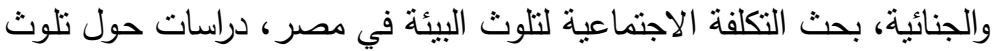
البيئة، النقرير الأول، القاهرة.

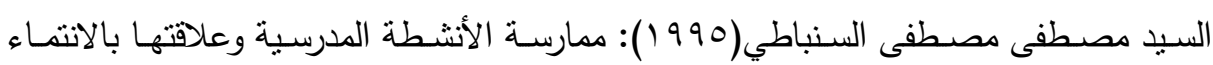

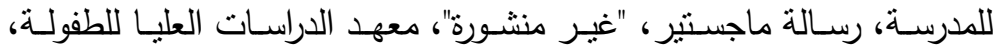

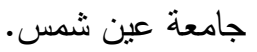

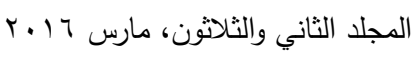




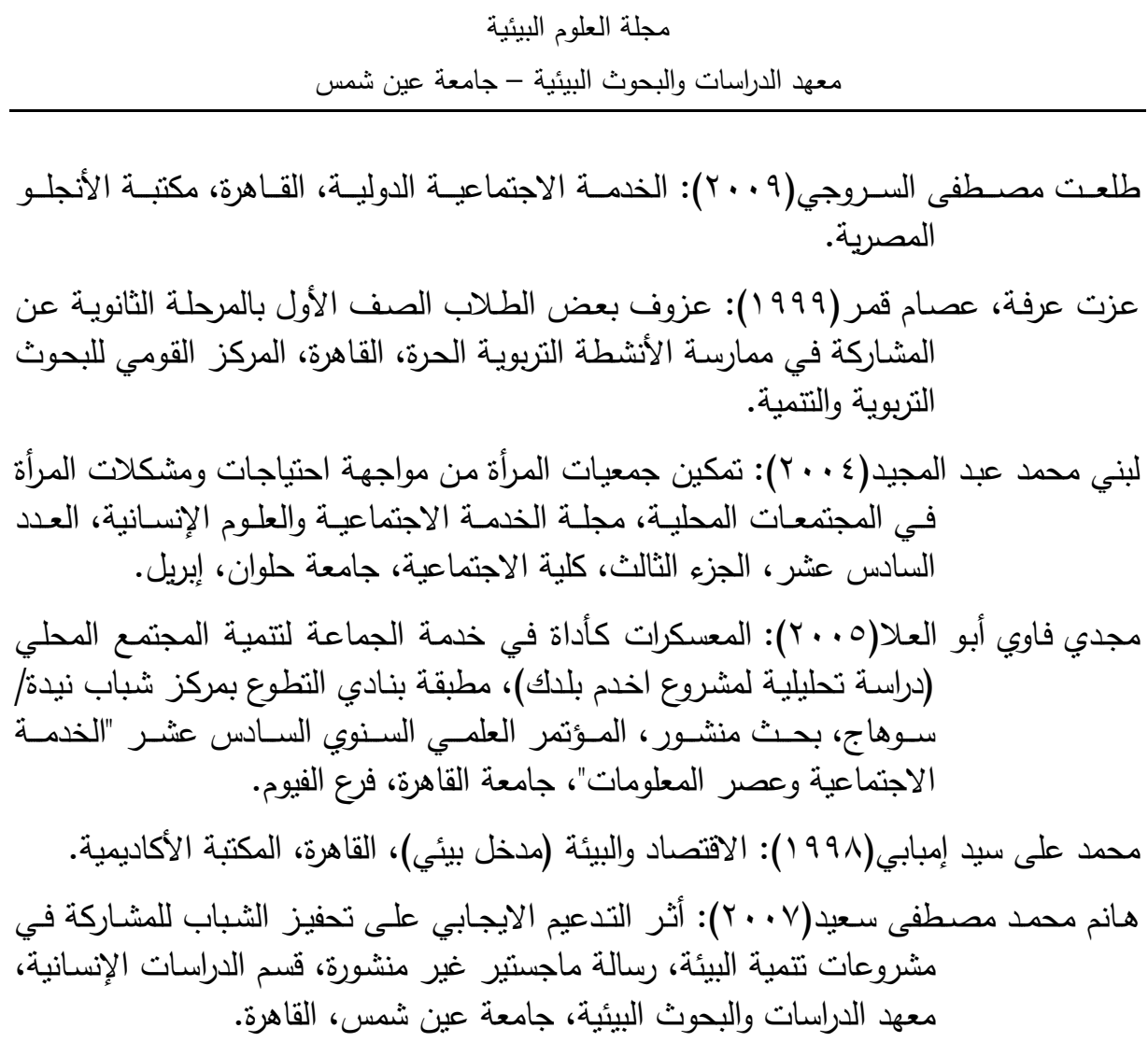

Bostic, Nina Crawford (2008), Knowledge, attitudes, and behaviors of college students in Family and Consumer Sciences towards environmentally friendly apparel, North Carolina State University, United States- North Carolina, Ed. D., Dissertations \& Theses.

Laura Wray-Lake (2010), Constance A. Flanagan, and D. Wayne Osgood, Environment and Behavior, January; vol. 42, Issue 1.

Nishiyama, Minako (2014), Environmental education as a catalyst for changing students' environmental attitudes: A survey of ten universities in the Tokyo Bay and San Francisco Bay Areas, Environmental Studies, United States- California, M.S., Dissertations \& Theses. 
علي محمود أبو ليلة وآخرون

Rowl Amds (1995), Empower Mpower Ment Examined "Development In practice Ox Fam. u. k.

\title{
ATTITUDES OF THE UNIVERSITY YOUTH TOWARDS ENVIRONMENTAL ISSUES AND THEIR REFLECTION ON SOCIETY DEVELOPMENT A FIELD STUDY
}

Lela, A. M. ${ }^{(1)}$;Gened, Hanan, F. ${ }^{(2)}$ and El-Ghanam, Manal, S. ${ }^{(3)}$ 1) Faculty of Arts, Ain Shams University 2) Faculty of Mass Communication, Cairo University 3) West Cairo Media Center, General Association for Information

\begin{abstract}
Drawn from this study that the environmental knowledge of university students are considered good, and that is the most important of these knowledge: Internet, followed by television . The study consisted of a sample of university students at AinShams University, consisted of ( 200 ) students (Female- Male) distributed (2) College (Theoretic- practical), this study belong to descriptive studies that based on analytical and social survey methodology. The researches depend on a questionnaire for university youth that participate in the congregation service and public form and strolling team in each faculty . This field study were confirmed the reality of study society, and identify the environmental knowledge, and trends for them, and the results show that there is great diversity in the problems faced by young people in order to protect the environment and the promotion of, and its development, and these problems may be the result of the State or the university, or family, or friends, and the role of the
\end{abstract}

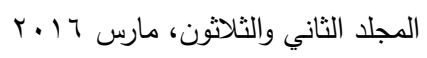


youth in the community development process is not commensurate with the expected role assigned to it, that has found many obstacles facing Youth and hindered from performing their role to the fullest, have been developed for the rational development of the local community environmentally social policy. and there are many beyond their control problems, which reaches them to a sense of helplessness and failure, , and the collision the old ideology and anti- development and innovation. It is clear that the extent of the apparent lack of both the state and its various institutions or individuals, in an attempt improve environmental protection and community development, and incapacitate young people to achieve this, the demolition of ambition and dreams, which may reflect the extent of the needs of this category of within the rest of Egyptian society, Which requires the presence of several mechanisms that enable young people to participate in local community development. 